\title{
AS PRÁTICAS COTIDIANAS DOS ASSISTENTES DE LINGUAGEM NA MINUSTAH
}

\section{Victoria Motta de Lamare França ${ }^{1}$}

\section{Resumo}

O presente artigo tem como objetivo refletir sobre o cotidiano dos intérpretes locais (Assistentes de Linguagem) empregados pela Missão das Nações Unidas para a Estabilização do Haiti (MINUSTAH). Acredita-se que esses profissionais conseguem criar uma sinergia entre a população local e os esforços internacionais protagonizados pela ONU. Dessa forma, a função exercida pelos Assistentes de Linguagem possibilita a construção de uma paz sustentável por garantir a voz e, consequentemente, a participação da população local. Nota-se que sem a capacidade de se comunicar com essa população no cotidiano da missão, a própria presença da ONU no terreno é questionável. Assim, a partir do ferramental teórico-metodológico da "virada prática" das Relações Internacionais, buscou-se coletar relatos e vivências de intérpretes e peacekeepers que atuaram no Haiti ao longo da Operação de Manutenção de Paz. Conclui-se que com a ausência de uma clara doutrina da ONU sobre esse tipo de profissional, o dia-a-dia desses intérpretes locais é marcado pela informalidade, colocando sua vida em risco, uma vez que os Assistentes de Linguagem não possuem o treinamento nem a ética profissional para a execução da função.

Palavras chave: Assistentes de Linguagem - Operações de Paz - MINUSTAH Interpretação - Mediação

\section{Abstract}

This article aims to reflect on the daily lives of local interpreters (Language Assistants) employed by the United Nations Stabilization Mission in Haiti (MINUSTAH). I believe these professionals can create synergy between the local population and international efforts led by the UN. Thus, the role played by the

\footnotetext{
1 Graduanda em Relações Internacionais pela Pontifícia Universidade Católica do Rio de Janeiro (PUC-Rio) e pesquisadora do Centro Conjunto de Operações de Paz do Brasil (CCOPAB). Lattes: http://lattes.cnpq.br/5616029757857705 Contato: vittimotta@gmail.com.
} 
Language Assistants enables the construction of sustainable peace, by ensuring the voice and, consequently, the participation of the local population. Without the ability to communicate with this population in the everyday life of the mission, the very presence of the UN on the ground is questionable. Thus, from the theoreticalmethodological tooling of the "practical turn" of International Relations, I sought to collect reports and experiences of peacekeepers and interpreters who worked in Haiti during the Peacekeeping Operation. I concluded that with the absence of a clear UN doctrine on this type of professional, the everyday life of this local interpreters is marked by informality, putting their lives at risk because the Language Assistants have neither the training nor the professional ethics to perform the profession.

\section{Keywords: Technological Advances - Holocaust - Genocide - Organization - Bureaucratic.}

\section{Introdução}

No contexto de Operações de Paz multidimensionais, ${ }^{2}$ como o caso da Missão de Estabilização das Nações Unidas no Haiti (MINUSTAH), deve-se considerar que diferentes culturas, nacionalidades e formas de ver o mundo se encontram muito devido ao número de países contribuintes e os hábitos e costumes da população local. Entretanto, o treinamento de um peacekeeper não o prepara totalmente para essa multiplicidade de pontos de vista. Além disso, outro ponto agravante é o fato de que para se comunicar, a capacidade de se expressar em uma outra língua que a materna é inversamente proporcional ao nível de estresse, que é cada vez mais alto em uma Operação de Paz, por conta do aumento progressivo do uso da força ${ }^{3}$ pelos capacetes azuis.

\footnotetext{
2 Existem diversas formas de se organizar o estudo sobre as Operações de Paz de forma cronológica ou se dedicando a temas específicos. O ponto levantado neste artigo sobre essa temática está relacionado à mudança nas tarefas das Operações de Paz com o Fim da Guerra Fria. Nesse contexto, as ações da ONU no terreno foram além do que era feito usualmente, como por exemplo a observação de cessar-fogo entre partes beligerantes. Agora, com a incorporação do componente civil, há um novo espectro de atividades relacionadas ao Estado de Direito, Direitos Humanos, eleições, perspectiva de gênero, proteção de civis, proteção de crianças entre outros. Para uma discussão maia aprofundada sobre a divisão das Operações de Paz em gerações para fins didáticos, ver Kenkel (2013).

${ }^{3}$ Os princípios que guiam as ações da ONU no terreno, conhecidos como a "Trindade Santa" das Operações de Paz, são: imparcialidade, consentimento do Estado anfitrião e uso mínimo da força (Kenkel, 2013). De fato, com as mudanças no contexto da globalização e a ascensão de "novas guerras" (Kaldor, 2013) levaram à flexibilização desses princípios. No entanto, estudiosos da área apontam para um ponto de inflexão significativo, sendo denominado como a "virada robusta" das Operações de Paz. Isso significa que a ONU está realizando alterações nas suas ações no terreno que vão de encontro a essas concepções. Isso pode ser evidenciado no momento em que as Operações de Paz ao serem autorizadas pelo Conselho de Segurança são nomeadas como Operações de estabilização. De fato, a ONU não possui uma doutrina sobre esse conceito, o que
} 
Assim, a solução encontrada pela Organização das Nações Unidas (ONU) para esse impasse é empregar a população local, porque a considera mais sensível em tais situações, especialmente na função de Assistente de Linguagem (field language assistant), ou seja, como intérprete local. Contudo, esse profissional não possui, na maior parte das vezes, treinamento adequado para exercer sua função, o que pode gerar uma série de desafios para se alcançar o objetivo da missão (United Nations Civil-Military Coordination, 2014, p. 129).

\section{Metodologia e Abordagem Teórica}

A fim de entender a posição deste profissional, este artigo se propõe a refletir sobre as práticas cotidianas implícitas na profissão de Assistente de Linguagem, procurando observar como o Assistente de Linguagem pode ajudar e/ou atrapalhar o andamento de uma missão (Bueger \& Gadinger, 2014, p. 3). Considera-se, então, o ferramental teórico-metodológico da virada prática nas Relações Internacionais, que pode ser caracterizada por um conjunto de abordagens que conferem maior centralidade nas relações cotidianas entre múltiplos atores com o objetivo de se investigar ordem e mudança (Bueger \& Gadinger, 2015).

Emmanuel Adler \& Vincent Pouliot (2011, p, 3) argumentam que com o foco nas ações estimuladas por atores internacionais no cotidiano, consegue-se entender tanto a dinâmica micro, aqui entendida como o nível individual, como também uma dimensão mais geral, podendo ser relacionada a uma organização ou até ao nível internacional. Para tanto, Rocha de Siqueira (2019, p. 96) lança luz na singularidade da virada prática, afirmando que:

A teoria da prática costuma oferecer a possibilidade de estudar instâncias difusas e sutis de poder. Isto não quer dizer que essas formas de poder sejam menos relevantes ou estejam relacionadas a aspectos menos danosos da política; pelo contrário, assim como no dilema apresentado acima, a teoria da prática é uma lente potencialmente interessante para quem se angustia a respeito de grandes questões, mas por várias razões, quer um olhar nem para baixo, nem para cima, nem dentro, nem fora, mas um olhar que existe em uma cumplicidade ontológica entre todos esses comuns dualismos das RI.

leva a interpretações tácitas no terreno, que são associadas ao aumento considerável do uso da força pelos peacekeepers. Esse é o caso da Missão de Estabilização das Nações Unidas no Haiti (MINUSTAH). Para mais informações, consultar: De Coning (2018), Mac Ginty (2012), Gorur (2016), Hunt (2017), Karlsrud (2019) e Muggah (2014). 
Dessa forma, as práticas do cotidiano, conceito central para o artigo, devem ser entendidas para além de meros comportamentos em sociedade. Entende-se que cada ação (comportamento dotado de propósito) tomada por um ator em sociedade pode se tornar uma prática a partir do estabelecimento de padrões, incorporados em contextos organizacionais específicos e desenvolvidos socialmente por meio de aprendizado e treinamento realizados ao longo de um tempo indeterminado (Adler \& Pouliot, 2011, p. 6).

Em suma, entende-se que as práticas dependem de três aspectos: (1) formas de atividades corporais e mentais, (2) artefatos ou "coisas" para seu uso e (3) um conhecimento de base, implícito ou tácito que organiza a prática e lhe fornece sentido (Bueger, 2014, p. 387). Ademais, os teóricos da prática assumem que todo conhecimento compartilhado é um conhecimento prático. Consequentemente, há um forte foco nas situações da vida cotidiana. Portanto, atividades e situações cotidianas são categorias centrais para as reflexões deste artigo.

Nessa perspectiva, o campo das Operações da Paz da ONU possui diversos atores militares, civis e policiais, de diversas nacionalidades (locais ou não), com objetivos e capacidades diferentes. Conceitos como a Paz Liberal ${ }^{4}$, Proteção de Civis $^{5}$, ajuda humanitária e democracia, por exemplo, uniformizam a percepção desses atores sobre as ações que eles devem exercer e as relações de autoridade no terreno. Nesse contexto, portanto, os Assistentes de Linguagem possuem uma função elementar, isto é, de permitir a comunicação entre esses atores, uma vez que eles detêm o conhecimento das línguas utilizadas por esses atores.

Assim, ao refletir sobre a temática do artigo, acredito que os Assistentes de Linguagem cumprem o papel essencial aproximando as duas principais partes de uma Operação de Paz. Entende-se, ainda, que o contexto de uma Operação

\footnotetext{
${ }^{4}$ A Paz Liberal é um conceito difundido e posteriormente contestado no campo das Operações de Paz. Na década de 1990, com o fim da Guerra Fria e o aumento exponencial do número de Operações de Paz sendo autorizadas pelo Conselho de Segurança, tinha-se como base para a criação de uma paz sustentável com princípios liberais. Eles estavam baseados em valores como a reconstrução e reforma estatal, a liberalização da economia, democracia. Essa visão teórica teve dificuldade de ser colocada em prática, por serem consideradas top-down, isto é, impostas de uma autoridade acima para um subordinado abaixo. Para defensores da Paz Liberal, ver Doyle (2012). Para a oposição à Paz Liberal, ver Paris (1997) e Richmond (2004, 2010) e Mac Ginty (2011). ${ }^{5}$ Semelhante ao conceito de Paz Liberal, a conceito de Proteção de Civis é derivado da inefetividade da ONU em seus empreendimentos da década de 1990 como Somália, Bósnia e Ruanda. Nesse cenário, os mandatos das missões não autorizaram o uso da força para proteger civis, somente a autodefesa dos capacetes azuis. O resultado disso foi um grande número de civis desprotegidos (genocídios) e capacetes azuis no terreno assistindo o que ocorria. A partir desse contexto, houve a mobilização dos países-membros da ONU para discutir um princípio legal que reorientasse a conduta das Operações de Paz, a Proteção de Civis. Ver Foley (2017).
} 
de Paz é complexo e, ao defender que a atuação dos Assistentes de Linguagem é fundamental para a comunicação entre o local e o internacional, não é objetivo deste artigo defender cegamente essa profissão, nem a perspectiva de um dos lados.

Torna-se necessário, entretanto, fazer uma ressalva relativa à coleta de dados. Assim, cumpre salientar que a pesquisa acerca do uso de Assistentes de Linguagem pela ONU em Operações de Paz é frustrada. Poucos são os dados, quantitativos e qualitativos, relevantes para uma reflexão da importância desses profissionais no terreno. Contudo, a falta de informação é um fator que estimula ainda mais a produção do artigo. Por outro lado, deve-se mencionar a ausência de uma vasta literatura acadêmica sobre o assunto. Esse artigo, portanto, procura responder a esse hiato.

Ao utilizar a abordagem da virada prática das Relações Internacionais aliada a reflexões sobre a linguagem, busca-se compreender o papel essencial dos Assistentes de Linguagem. Este artigo, então, procurará usar o método qualitativo, entendendo que apesar de muitos trabalhos utilizam a virada prática meramente para fazer reflexões teóricas, é necessário buscar uma empiria (Bueger \& Gadinger, 2014, p. 77).

Propõe-se, portanto, uma "praxiografia"6, isto é, uma proposta de método que englobasse as diferentes formas de se investigar as relações de poder por meio da prática. Entende-se essa concepção como a reconstrução de significados nas relações sociais, recaindo, portanto, em uma abordagem de pesquisa interpretativa e qualitativa. Assim, busca-se refletir sobre a relação entre os três aspectos definidores das práticas citados acima (Bueger, 2014, pp. 387-388).

Dessa forma, optou-se por entrevistar um Assistente de Linguagem ${ }^{7}$ que trabalhou na MINUSTAH para ilustrar os desafios a serem expostos, bem como um intérprete profissional militar do Centro Conjunto de Operações de Paz do Brasil (CCOPAB) que trabalhou em uma posição de supervisionar os Assistentes de Linguagem. Escolhi essa abordagem, porque melhor se adequa à

\footnotetext{
${ }^{6}$ Esse conceito é derivado de uma comparação entre o método etnográfico e os estudos propostos pela virada prática. Ao comparar os dois métodos, pode-se considerar as dificuldades na coleta e seleção de informação, questões como imersão/imparcialidade do pesquisador e problemas de escala para análise, por exemplo, como pontos de convergência. Todavia, em relação às divergências com a etnografia, a praxiografia busca focar na dimensão prática (dotada de conhecimento tácito ou implícito), em vez de uma visão mais cultural. Ver principalmente Bueger (2014) e Bueger \& Gadinger (2014, pp. 80-81).

${ }^{7}$ Esta entrevista foi realizada por Giulia Lopes, uma vez que a primeira versão deste artigo foi um trabalho em conjunto para a disciplina de "Estudos de Operações de Paz" em 2018. Assim, a autora agradece a seção do material transcrito que é utilizado nesta reflexão.
} 
disponibilidade para a execução desta pesquisa ${ }^{8}$. Assim, acredita-se que, mesmo sendo visões únicas de um acontecimento, as entrevistas são fontes primárias para essa reflexão, logo o seu uso tem como objetivo "adquirir pistas sobre o conhecimento prático de alguém que é participante da prática" (Bueger \& Gadinger, 2014, p. 89). Ao mesmo tempo, será possível colocar duas narrativas em choque: a do profissional e de quem utiliza o serviço.

Assim o restante do artigo está dividido em duas seções principais seguidas de considerações finais. Primeiramente será abordado o trabalho de um Assistente de Linguagem em Operações de Paz e, em seguida, propõe-se refletir sobre sua participação na Missão no Haiti por meio de dados obtidos pelas entrevistas.

\section{As Relações Local/Global e o Emprego de Assistentes de Linguagem em Operações de Paz da ONU}

Com objetivo de entender melhor como os Assistentes de Linguagem se engajam em Operações de Paz, esta seção procura explorar de quais formas esses atores se inserem e como eles conseguem incidir e/ou serem afetados por esse contexto. Dessa forma, as Operações de Paz da ONU são um rico objeto de estudo, uma vez que permitem analisar diversas dinâmicas e tensões tipicamente analisadas em um nível macro pelas Relações Internacionais. Ao focar na fronteira entre o local e o global, amplamente questionada pela disciplina, este artigo entende que a linguagem consegue rompê-la, uma vez que a comunicação é minimamente estabelecida pelas partes.

As Nações Unidas, ao realizarem uma Operação de Paz em diversos países, se deparam com o desafio de ultrapassar as barreiras linguístico-culturais presentes nas interações entre a população local e o internacional, representado pelas tropas da ONU (Baker, 2010, p, 155). Nesse sentido, a presença e os objetivos da ONU podem ser questionados no terreno se os capacetes azuis não conseguem dialogar com o que é receptor e/ou parceiro no projeto de consolidação da paz. Com isso, fica marcado que uma "ponte" é essencial para a alcançar os objetivos do mandato ${ }^{9}$ sendo concretizada pelos Assistentes de

\footnotetext{
${ }^{8}$ Para uma revisão sobre as vantagens e limitações de entrevistas como método de análise ver Gi (2008, p. 109-111).

${ }^{9}$ O mandato de uma Operação de Paz é um documento emitido pelo Conselho de Segurança das Nações Unidas por meio de uma Resolução, que busca delimitar a diretriz que a missão deve adotar. Nele, há a indicação de qual capítulo da Carta das Nações Unidas está baseada a missão, apontando o nível de força a ser adotado pelos capacetes azuis no terreno, quanto tempo durará a missão, seus objetivos, entre outros.
} 
Linguagem, uma vez que essas pessoas são capazes de falar os idiomas locais e os da missão internacional (Hale, 2007, p. 16).

Nesse sentido, cabe também ser feita a distinção entre os trabalhos de tradução e interpretação ${ }^{10}$. O primeiro se dedica à transposição de uma mensagem especialmente escrita entre dois idiomas, já o segundo trata de questões verbais entre locutores (nota-se a ausência de um texto-base). Com isso, a interpretação é feita com mais urgência e possui um conjunto de técnicas específicas para sua realização. Nessa perspectiva, a tradução se aproxima mais de um monólogo, já a interpretação, um diálogo, o que lhe atribui uma dificuldade maior com a necessidade de continuidade na produção de sentidos ao longo de uma conversa (Hale, 2007).

Apesar de não ser o foco do artigo, cabe citar que ainda no escopo da interpretação, há diferentes ocupações, como intérpretes de conferência, por exemplo, que se diferenciam do tipo de interpretação focado nesta reflexão, por exemplo na questão da formalidade, do equipamento disponível e das modalidades de interpretação utilizadas (consecutiva, simultânea ou chouchotage). No caso do objeto de estudo deste artigo, o Assistente de Linguagem na MINUSTAH, entende-se que ele se aproxima mais do conceito de interprete comunitário, ou seja, um profissional que atua em situações mais cotidianas, se em comparação a congressos, por exemplo (Hale, 2007).

Outras divergências entre esses dois tipos de interpretação abrem espaço para começarmos a entender os desafios vividos pelos Assistentes de Linguagem e as pessoas que dependem desse serviço. Por exemplo, no caso de uma conferência, é comum as partes já terem conversados informalmente, bem como haver um documento final da reunião que pode esclarecer equívocos da interpretação. Já no caso de reuniões intermediadas pelo Assistente de Linguagem, elas são mais urgentes e há uma questão de confidencialidade envolvida. Como afirma Hale:

$\mathrm{Na}$ interpretação comunitária, a necessidade dos serviços do intérprete pelos participantes é real, porque eles simplesmente não seriam capazes de se comunicar sem eles (...). Isso sugere que o ônus do intérprete comunitário em executar um trabalho de alta qualidade é muito maior do que um intérprete de conferência por causa do que está em jogo. No entanto, os intérpretes comunitários, com demandas muito maiores que os de conferência, recebem

\footnotetext{
10 Nos Estudos de Tradução e Interpretação, esses dois conceitos são considerados como tipos ideais, separados por um espectro de ações possíveis para os profissionais da área. Dessa forma, cabe citar especializações como a tradução, legendagem, tradução à vista, interpretação simultânea, interpretação consecutiva longa, interpretação de diálogo e chouchotage (sussurrado). Para mais informações, ver Souza Junior (2016) e Hale (2007, pp. 8-14). No caso do trabalho dos Assistentes de Linguagem, entende-se que seu dia-a-dia se assemelha mais com o lado do espectro da interpretação, já que ele realiza principalmente a interpretação de diálogo.
} 
salários muito mais baixos e têm pouco status de profissionais (Hale, 2007,p. 3233, tradução nossa).

Assim, este artigo se propõe a focar nos desafios dos trabalhadores nativos que cumprem somente o papel de interpretação, ou seja, o esclarecimento das falas dos dois principais lados em uma missão: os peacekeepers e a população local. Com isso, uma série de questões serão levantadas sobre as peculiaridades desta situação. Por outro lado, vale ressaltar que a questão de tradução de documentos oficiais cabe ao pessoal treinado em Tradução e Interpretação, que geralmente faz parte das tropas de países que contribuem para as Operações de Paz.

Ademais, é preciso levar em consideração que esses indivíduos geralmente não possuem certificação de sua proficiência nos idiomas que trabalham, geralmente o inglês ou o francês (por serem tipicamente as línguas das Operações de Paz da ONU) e sua língua materna, muito menos treinamento formal como intérpretes, o que os leva a recorrer a técnicas de tradução que podem perder um sentido prático ${ }^{11}$ da mensagem (Organização das Nações Unidas, 2009, p. 16). Esse caráter informal do trabalho desses intérpretes é explorado por Antonini et al. (2017), com o conceito de intérpretes não profissionais.

Esses autores defendem a ideia de que sempre existiram pessoas não treinadas que realizassem interpretações, como, por exemplo, crianças bilíngues. Nesse sentido, esses indivíduos (podendo também ser chamados na literatura de intérpretes naturais, language brokers ou intérpretes ad hoc) são parte da comunidade de interpretação, mesmo sem treinamento na área e com pouco reconhecimento (Antonini et al., 2017). Com isso, este artigo lança luz a um tipo de intérprete não profissional, os Assistentes de Linguagem, a fim de refletir sobre seu papel de mediador das interações entre local e global em Operações de Paz. No entanto, independentemente da capacidade ou do treinamento do profissional, vale ressaltar que sempre haverá uma perda na tradução ou interpretação, devido

\footnotetext{
${ }^{11}$ Há uma longa discussão na área de Tradução e Interpretação acerca do que se deve focar no processo de transpor uma mensagem do idioma-origem para o idioma-destino, variando, portanto, na importância de fidelidade ao texto original. Foca-se no princípio da relação de equivalência, isto é, a crença de que é possível, mesmo que não literalmente, passar uma mensagem de uma língua para outra, já que há uma relação de signos e significantes entre elas. Assim, intérpretes pouco experientes vão se dedicar a realizar interpretações que são mais literais ou que focam mais em uma questão semântica. Essa segunda modalidade, a mais próxima da realidade do Assistente de Linguagem em uma Operação de Paz, provoca a perda do sentido da mensagem, já que a interpretação fica desprendida do contexto. Por outro lado, intérpretes com mais experiência e um treinamento mais formal tendem a se preocupar com o sentido pragmático da mensagem, ou seja, realizar a interpretação levando em conta as peculiaridades do contexto e as necessidades dos interlocutores. Todavia, isso vai de encontro ao código de ética da profissão, que prega pela tradução in verbatim do que é dito (Hale, 2007, p. 22-24).
} 
ao caráter excepcional de cada idioma. No entanto, ao utilizar um pessoal não treinado para a função, há um aumento do potencial de mal-entendidos ${ }^{12}$.

Isso significa que essas pessoas são postas em condições de trabalho para as quais não há formação ou orientação de como prosseguir, muito menos a ética profissional necessária para apoiar a gestão de crises e os esforços humanitários em um ambiente estressante (Moser-Mercer \& Bali, 2008). Assim, o emprego desses profissionais pode se constituir em um risco para os objetivos da Operação de Paz, para a vida dos capacetes azuis, da população civil e dos próprios intérpretes.

Nessa perspectiva, a fim de exercer a profissão de Assistente de Linguagem em uma Operação de Paz das Nações Unidas, é necessário uma série de requisitos, presentes desde a divulgação das vagas pela $\mathrm{ONU}^{13}$, podendo se resumir em três competências: comunicação, profissionalismo e client orientation. Primeiramente, é demandado ${ }^{14}$ do candidato a habilidade linguística para concisa comunicação verbal, além de conseguir romper as barreiras linguísticas e culturais existentes entre dois ou mais atores, por exemplo o componente militar e grupos locais. É preciso também ser capaz de fazer a interpretação de maneira rápida e sem o auxílio de um dicionário (Souza Júnior, 2016, p. 4).

Ademais, vale ressaltar que as línguas das Nações Unidas são o árabe, o chinês, o espanhol, o francês, o inglês e o russo. Desse modo, o intérprete necessita ser capaz de transformar a mensagem dos idiomas locais para pelo menos um dos idiomas da Missão (escolhidos entre os oficiais da ONU) e de volta para as línguas locais. Esse tipo de exigência pode parecer simples, porém, no terreno, é difícil para um civil ter conhecimento sobre vocabulário técnico militar, por exemplo.

\footnotetext{
12 Sandra Hale (2007, p. 14-21) considera diversas fontes para a criação de mal-entendidos durante o processo de interpretação, podendo ser divididos entre internos ou externos ao discurso. No que tange a dimensão interna, o intérprete pode não ter um conhecimento aprofundado o suficiente do par de línguas sendo trabalhado ou o locutor pode formar um discurso incoerente, não querer ser entendido ou usar expressões ambíguas. Já na dimensão externa ao discurso, deve-se considerar as condições físicas do lugar onde a interpretação está sendo feita (é possível escutar com clareza o que está sendo dito?) e o entendimento do locutor sobre o papel e as necessidades do intérprete. Ainda na dimensão externa, o intérprete pode não ter uma boa compreensão sobre os papéis sociais dos participantes, os papéis de discurso na interação, além do contexto, do cenário, das culturas e do assunto sendo discutidos.

13 Para maiores informações, tendo em vista que as vagas são postadas e retiradas do ar com frequência, ver uma vaga para a profissão de Assistente de Linguagem de campo (Field Language Assistant) relacionados a alguma Operação de Paz da ONU em andamento em careers.un.org

${ }^{14}$ Há um debate acerca de modelos em relação ao papel e qualidade de um interpretador que focam mais em sua neutralidade ou em sua capacidade de aproximação cultural. Ver Businaro (2012, p. 11).
} 
Outro ponto relevante para a configuração desse mosaico é que há um agravante na escolha do idioma da Operação de Paz, uma vez que isso afeta a percepção local sobre a legitimidade da ONU. Nessa perspectiva, espera-se uma sensibilidade das Nações Unidas ao tomar essa decisão. No caso do Haiti, o créole é a língua falada pela maioria, entretanto, a elite é proficiente em francês e a MINUSTAH tem como línguas oficiais o francês e o inglês (Edwards, 2001). Ademais, vale ressaltar que a maior parte das pessoas que compõem os componentes de uma missão falam sua língua materna e o inglês, já a maior parte dos lugares em que as Operações de Paz ocorrem tem idioma menos comuns, como é o caso do Haiti (Carbonell et al, 2006, p. 1).

Assim sendo, com o objetivo de utilizar uma voz da área de Tradução e Interpretação, a fundadora da Translators Without Borders, Lori Thicke, destaca que as pessoas fornecem ajuda todos os dias em idiomas de origem europeia, como, inglês, francês e português. Com isso, é criada uma barreira entre a ajuda humanitária internacional e a população local, que fala línguas locais (Tran, 2012). No caso do Haiti, a escolha da abordagem linguística tem consequências para a efetividade dessa ajuda. Dessa forma, ao criar uma Operação de Paz onde as línguas oficiais não atingem a maior parte da população pode ser um problema, para o qual um local exercendo a função de intérprete ambiciona se tornar uma solução prática.

Em segundo lugar, as diretrizes da ONU para o cargo de Assistente de Linguagem impõem uma questão de profissionalismo, contemplando, por exemplo, uma imparcialidade em relação ao conflito. Isso quer dizer, então, que não é permitido ao trabalhador escolher um lado da guerra ao exercer a profissão, principalmente por conta da legitimidade da missão na qual ele está trabalhando. Contudo, isso se mostra um desafio, uma vez que esse indivíduo se encontra previamente inserido na comunidade onde se dá o conflito e seus precedentes.

Esse agravamento pode Ihe ter concebido algum tipo de aversão em relação à guerra ou a algum dos lados, dificultando sua ação no auxílio das negociações. A título de exemplo, se um Assistente de Linguagem estiver fazendo a interpretação de um diálogo entre um peacekeeper e um ex-combatente, não cabe ao profissional fazer juízo de valor sobre aquela pessoa, porque ela participou do lado $X$ do conflito. Mesmo assim, este artigo reconhece que a real imparcialidade é impossível e entende que o objetivo da ONU ao solicitar esse requisito é que o intérprete não profissional consiga se aproximar ao máximo desse tipo ideal. 
Ainda na questão de imparcialidade, cabe ressaltar que é preciso que o Assistente de Linguagem seja capaz de manter uma certa distância para evitar seu esgotamento emocional. Vale lembrar que essa profissão conta constantemente com um sentimento de estar preso no meio de conflitos e dilemas de outros (Bishoff \& Loutan, 2008, p. 43). Com esse tipo de questão levada a evidência, vale lembrar que a ONU não possui uma diretriz bem definida para a realização dessas funções e, situações pessoais como esgotamento psicológico e emocional podem ser deixadas de lado.

Convém, ainda, lembrar que esses profissionais são civis e, mesmo inseridos em um contexto de conflito ou desastre natural, não estão habituados com as pressões cotidianas do contexto militar e de negociações (Souza Júnior, 2016, p. 10). Assim sendo, uma situação de muito estresse pode diminuir a eficiência de seu trabalho e comprometer uma possível reunião, uma vez que só o Assistente de Linguagem conseguiria cumprir sua função nesses encontros e os lados presentes provavelmente não entenderiam se houvesse um problema com o outro.

Mesmo em uma situação de profissionais treinados trabalhando em um ambiente menos estressante, como, por exemplo, uma negociação entre dois ou três representantes de governos, onde há menos distúrbios do som, não é recomendado que um intérprete realize seu trabalho por mais de 30 minutos consecutivos. Isso acontece, tendo em vista que é um trabalho cansativo e tende a piorar sem o devido descanso. Logo, é comum esses intérpretes trabalharem em duplas, para que um possa substituir o outro.

Contudo, esse não é um caso do cotidiano nas Operações de Paz da ONU. O Assistente de Linguagem costuma acompanhar um batalhão ou uma parte dele para a realização de tarefas que envolvam o contato com a população local. Dentre elas, cabe citar momentos de conscientização da população em relação a questões de atividades da ONU na localidade, como quick-impact projects $^{15}$, conscientização sobre gênero e saúde.

15 Os Quick Impact Projects (QIPs) podem ser entendidos à luz do artigo de Eduarda Hamman, Henrique Garbino e Maiara Folly (2017, p. 1) como "projetos de pequena escala e baixo custo, que têm por objetivo principal consolidar a confiança da população local na missão e no processo de paz de maneira geral. Ou seja, embora sejam pontuais e relativamente pequenos, os QIPs estão inseridos em uma estratégia mais ampla e têm impactos significativos na transição para o desenvolvimento e para a paz sustentável". No caso do Haiti, vale levantar duas questões relevantes sobre o assunto: a desconfiança da população local sobre o governo transitório e os desastres naturais ocorridos ao longo da missão. Esses dois aspectos tornaram os QIPs peça fundamental nos esforços da ONU no terreno, uma vez que passaram a incidir sobre os objetivos fundamentais elencados no mandato. Entre julho de 2004 e setembro de 2015, período analisado no artigo, mais de 1.600 projetos foram financiados pela MINUSTAH, com um orçamento de quase US\$ 42 milhões. 
Em terceiro lugar, é preciso ter uma sensibilidade quanto às tradições locais. O intérprete deve ser capaz, portanto, de informar ao peacekeeper sobre as peculiaridades das comunidades locais, como por exemplo costumes, expressões, gestos pejorativos, lugares para reunião, datas especiais, vestimenta adequadas, etiqueta, entre outros. Igualmente importante é a sensibilidade de gênero, isto é, em algumas culturas, algum dos gêneros podem não ser bem vistos como participante das negociações, seja como Assistente de Linguagem ou peacekeeper (United Nations Civil-Military Coordination, 2014, p. 129).

Nessa perspectiva, pode parecer que o uso de Assistente de Linguagem pode comprometer a Operação de Paz mais do que ajudar. O leitor pode ser levado a entender que adicionar mais um elemento na equação peacekeeper e população local pode levar a um desastre na comunicação e nos esforços de paz. Muito pelo contrário, como explica Souza Júnior, os intermediários culturais cumprem um papel essencial:

Por que utilizá-los se não são profissionais, então? Simplesmente pelo fato de não haver intérpretes profissionais que atuem em pares de idiomas ou dialetos tão específicos como os encontrados nas diversas áreas de missão, e também, porque esses indivíduos conhecem bem a cultura local. Eles atuam como se fossem o porta-voz de Relações Públicas do soldado da paz ou do civil empregado na área da missão; podendo dar sugestões sobre a melhor forma de se proceder com a população local, de variados costumes e cultura, identificando, ainda, nuances e sutilezas que, por nós, poderiam, facilmente, passar despercebidas (Souza Júnior, 2016, p.5, grifo nosso).

Um dos momentos de maior importância para o trabalho dos Assistentes de Linguagem é sua atuação em uma espécie de briefing quando um observador militar $^{16}$ da ONU chega primeiramente no terreno. Vale lembrar que há uma grande rotatividade desses profissionais não armados em Operação de Paz, logo há pouco tempo de preparação e alto risco de desinformação sobre os costumes da população local na missão. Assim, seu papel de passar rapidamente informações sobre a vida local para uma chegada pacífica dos Observadores Militares da ONU são fundamentais para esses observadores (Kelly \& Baker, 2013).

Ademais, há a percepção de que o emprego da população local aumenta a legitimidade da missão nos olhos da comunidade local, algo já visto pelos

\footnotetext{
16 O observador militar é uma função considerada como individual em uma Operação de Paz, diferentemente da contribuição com tropas, situação a qual um grupo de militares é empregado, como no caso de um dos entrevistados que fez parte de uma Companhia de Engenharia de Operações de Paz. As atividades comuns realizadas no cotidiano estão mais relacionadas a confecção de relatórios, logo torna-se claro a importância da percepção situacional para esse tipo de profissional. Mesmo assim, apesar do treinamento oferecido nos centros de treinamento a partir dos parâmetros definidos pela ONU, a possibilidade de ter acesso ao Assistente de Linguagem oferece ao observador uma visão diferencial para a realidade do terreno.
} 
militares em seus relatos sobre as missões. Isso é entendido por esses profissionais, porque os cidadãos daquele país podem entender que um local trabalhando na Operação de Paz é um sinal de comprometimento da Missão em incorporar a visão local no processo de construção da paz. Além disso, cabe ressaltar que os Assistentes de Linguagem são usualmente figuras influentes em sua região, devido ao seu grau de escolaridade ser geralmente mais alto do que a média da população (Organização das Nações Unidas, 2009, p. 16).

Nessa perspectiva, de acordo com os manuais utilizados pela ONU, como o Specialised Training Materials (STM) para instruir as tropas que farão uso do serviço dos intérpretes, um equívoco na interpretação por parte do Assistente de Linguagem consiste no principal risco de se empregar profissionais não certificados e treinados para exercer essa função. Isso pode levar ao comprometimento das negociações com um dos atores da missão ou até pôr em risco de vida a tropa ou o próprio assistente (United Nations Civil-Military Coordination, 2014, p. 129).

Com isso, é importante dedicar tempo para a preparação antes das reuniões segundo Souza Júnior (2016, p. 13). Nesse momento, o peacekeeper tem o dever de informar seus intérpretes o que acontecerá no encontro, qual é seu objetivo e como pretende-se alcançá-lo, levando sempre em consideração questões de confidencialidade. Ademais, caso considerar necessário, pode-se também revisar algum vocabulário técnico extraordinário, a fim de diminuir a probabilidade de mal-entendidos, justamente, porque o intérprete pode não estar familiarizado com um vocabulário militar, por exemplo (Bischoff \& Loutan, 2008, p. 33; Organização das Nações Unidas, 2009, p. 17; Hale, 2007).

Contudo, cabe ressaltar que pode também acontecer o oposto nessas reuniões, em um outro caso do Assistente de Linguagem conhecer profundamente o assunto. Assim, o peacekeeper pode se surpreender com a contribuição de intérprete. Dessa forma o trabalhador pode, por exemplo, ser um ex-combatente em algum conflito em sua região e, portanto, poderá possuir uma sabedoria considerável sobre a tecnologia militar. De qualquer forma, cabe ao peacekeeper conhecer seu intérprete e saber como melhor usar seus serviços para atingir os objetivos da missão.

Outro fato a ser considerado é seu local de moradia, uma vez que o intérprete não reside na base da ONU, ou seja, o local teoricamente mais seguro da região. Pode-se concluir que, se um profissional mora em uma área considerada "território" de interesse de uma das partes de um conflito, ele poder 
ser associado a ela. Desse modo, perde-se o vínculo esperado pelo ONU com a sua imparcialidade, podendo, então, perder seu emprego.

\section{O Cotidiano dos Assistentes de Linguagem na MINUSTAH}

Esta seção tem como objetivo refletir sobre o cotidiano dos Assistentes de Linguagem na Missão das Nações Unidas para a Estabilização no Haiti (MINUSTAH) a partir de vivências e relatos coletados. Busca-se evidenciar a sinergia entre o local (cidadãos do país anfitrião, nesse caso, o Haiti) e o internacional (representado pelas tropas de países que contribuíram para a MINUSTAH) por meio das práticas cotidianas dos Assistentes de Linguagem, ou por conta da ausência delas. Haverá, primeiramente, uma contextualização da MINUSTAH, seguida de reflexões do material coletado (entrevistas). Defendo, portanto, que a presença de um intérprete local que consiga realizar uma ponte eficiente entre esses dois tipos de atores é fundamental para que as ações da ONU no terreno ocorram.

Estabelecida em 2004, a Operação de Paz da ONU intitulada MINUSTAH se deu por conta da situação em que o Haiti se encontrava: o ex-presidente do país, Jean-Bertrand Aristide, renunciou ao cargo após acusações a respeito de eleições fraudulentas e uma revolta da população quanto a economia e a corrupção que assolavam o país. Além disso, vale constar que havia várias gangues, milícias e grupos sectários da Polícia Nacional do Haiti ${ }^{17}$. Nesse contexto, relatórios do Secretário-Geral da $\mathrm{ONU}^{18}$, bem como os esforços insuficientes da Força Multinacional Interina (MIF, do inglês) ${ }^{19}$ levaram a Resolução 1542 do Conselho de Segurança, que estabelecia a MINUSTAH (Conselho de Segurança das Nações Unidas, 2004c).

Dessa forma, o mandato inicial da MINUSTAH buscava conter a deterioração política e a escalada da violência no país, com o objetivo de defender um ambiente seguro, onde a democracia poderia ser plenamente exercida (Conselho de Segurança das Nações Unidas, 2004c). Vale, ainda, ressaltar que os Assistentes de Linguagem foram empregados desde o início da Operação, uma vez que as línguas oficiais eram inglesas e francesas, enquanto que a maioria da população falava créole.

\footnotetext{
17 Do francês, Police Nationale d'Haiti.

18 Consultar, por exemplo, a Resolução do Conselho de Segurança das Nações Unidas (2004a).

${ }^{19}$ Consultar a Resolução do Conselho de Segurança das Nações Unidas (2004b) para o mandato da MIF.
} 
Em 2010, as eleições marcadas foram adiadas, devido ao grande terremoto ${ }^{20}$ que afligiu o país em janeiro daquele ano, seguido por um surto de cólera $^{21}$. Entre as 102 mortes de trabalhadores da ONU, incluem-se três Assistentes de Linguagem, que atuavam fazendo tradução de documentos importantes e como intermediários entre a população local e policiais que faziam patrulhas nas cidades (Organização das Nações Unidas, 2010). Vale ressaltar que essa é uma das poucas menções públicas da ONU sobre seus intérpretes no terreno.

Durante os 13 anos da MINUSTAH (2004-2017), a experiência da ONU com Assistentes de Linguagem foi fundamental para o dia-a-dia da missão e impulsionou alguns Centros de Treinamento para Operações de Paz referentes dos países participantes da MINUSTAH a investirem em um departamento de Interpretação e Tradução a fim de oferecer treinamento linguístico e cultural para suas tropas para cada missão. Esse foi o caso da Brasil, que criou o Estágio para Tradutores e Intérpretes Militares (ETIM) 22 em 2011 (Souza Júnior, 2015, p. 12).

Kelly \& Baker (2013) afirmam que esse caso é muito comum em Operações de Paz, uma vez que, é razoável pensar que nos países contribuintes de tropas não há um amplo número de soldados fluentes em todos os idiomas do mundo. Assim, uma resposta mais imediata é contratar intérpretes locais e impulsionar cursos como o ETIM, mesmo que os Assistentes de Linguagem permaneçam necessários durante toda a missão. Isso mostra, portanto, a materialidade por trás de práticas sobre a interseção entre linguagem e Operações de Paz, algo fundamental para a virada prática das Relações Internacionais (Bueger \& Gadinger, 2015, p. 4; Adler \& Pouliot, 2011).

Com o intuito de exemplificar a comunicação cotidiana estabelecida pelo trabalho dos intérpretes entre os peacekeepers e a população local, coletou-se material acerca do cotidiano dos Assistentes de Linguagem na MINUSTAH por meio de entrevistas. Esse método foi utilizado, devido ao escopo possível de atuação da pesquisadora. Como afirma Bueger (2014, p. 400), as entrevistas podem ser criticadas por alguns estudiosos das práticas, uma vez que elas são

\footnotetext{
${ }^{20}$ Foi feito um estudo sobre a rede de tradutores e intérpretes profissionais ou não (Antonini et al. (2017) no caso do terremoto do Haiti. Nele, busca-se refletir sobre a conectividade da internet, bem como as ferramentas tecnológicas que proporcionaram uma rápida convocação de ajuda humanitária. Para mais informações, ver Rogl (2017).

${ }^{21}$ Esse caso foi alvo de amplas discussões sobre a função de peacekeepers no terreno. Ver, por exemplo, Sengputa (2016).

22 Vale notar, entretanto, que o ETIM era um projeto embrionário, uma vez que abarcava somente a parte mais prática da profissão e era feito em pouco tempo. Em 2013, ao alinhar-se com os padrões de preparo determinados pelo Departamento de Operações de Paz da ONU (DPO) foi criado um novo curso, o ETMIL, que conta com 120 horas de estudos teóricos da área. Assim, pode-se afirmar que houve um espaço maior para uma reflexão sobre a função (Souza Júnior, 2015, p. 15).
} 
reflexões posteriores ao acontecimento que refletem o comportamento de um ator individual. Contudo, elas permitem desvendar as estruturas implícitas de significado, que somente alguém experiente tem acesso, algo fundamental para a reflexão deste artigo.

Ao considerar que os entrevistados estavam inseridos na Operação de Paz e realizaram funções de interpretação e/ou trabalhavam com os Assistentes de Linguagem, busca-se reconstruir as ações cotidianas detalhadas, perguntando como os entrevistados realizavam certas atividades que fazem parte da prática, portanto expondo suas motivações e conhecimentos. "Como uma entrevista geralmente é realizada em diálogo, o entrevistador e o entrevistado reconstroem o significado juntos; eles coproduzem uma interpretação de práticas" (Bueger, 2014, p. 400, tradução e grifo nosso).

As seções a seguir buscam sistematizar os dados apurados pelas entrevistas com um intérprete não profissional local (haitiano) e um intérprete profissional militar (brasileiro), que atuaram na MINUSTAH em diferentes contextos. Optou-se por essa divisão a partir do conteúdo divulgado pelos entrevistados. Assim, busca-se considerar a importância da presença do intérprete em ações cotidianas e, em seguida, refletir sobre sua formação e os desafios de seu emprego na MINUSTAH.

\title{
i. Importância do Assistente de Linguagem em Mediações Linguístico- Culturais
}

\begin{abstract}
De modo geral, os encontros não podem ser realizados sem a presença de um intérprete, porque sua qualidade depende da qualificação [do intérprete] e do tamanho do impacto [da mensagem], que tem a ver com o resultado esperado, quantidade de pessoas a alcançar, nível social e educativo. Em resumo, um bom intérprete também é um sociólogo, psicólogo, mediador, animador, professor e até mais. (Intérprete não profissional haitiano).
\end{abstract}

Esta seção busca relacionar como a presença de um intérprete local impacta a condução da MINUSTAH. Para ilustrar esse argumento, expõe-se dois exemplos, onde há uma ação sendo realizada entre a população local e o internacional (civis e militares). A primeira busca mostrar como a ausência de um intérprete pode comprometer os objetivos da missão, enquanto que a segunda apresenta um exemplo de tarefa cotidiana para o Assistente de Linguagem.

De acordo com Igor Kipman, Embaixador do Brasil no Haiti entre 2008 e 2012, é costumeiro no Haiti fazer o movimento de um punho fechado como forma 
de agradecimento, entretanto, para a cultura estadunidense, esse gesto pode ser considerado hostil. Com essa diferença cultural em mente, configura-se o seguinte cenário. Havia representantes da comunidade internacional, sendo escoltados por tropas compostas, em parte, por estadunidenses. Assim, enquanto esses civis que estavam entregando suprimentos e prestavam assistência à população, os haitianos (dentre eles crianças), receptores dessa ajuda, demonstraram agradecimento mostrando o punho fechado (Kipman, 2019, p. 147).

Mesmo com um objetivo amistoso e pacífico, as ações do povo local geraram tensões ao serem mal interpretadas. A situação, antes um momento pacífico de ajuda humanitária, se transformou em um ambiente violento, que envolvia o corpo militar de assistência pronto para se defender por acreditar que a população local os estivessem ameaçando. O caso só foi solucionado sem o uso da violência por conta do conhecimento tácito da Embaixatriz Roseana Kipman, que explicou o significado do gesto para as tropas estadunidenses (Kipman, 2019, p. 147).

Nota-se que esse tipo de situação poderia ser evitado, ou pelo menos rapidamente resolvido, caso um Assistente de Linguagem estivesse presente para alertar a possível ambiguidade do gesto. De fato, não necessariamente 0 intérprete conhece as culturas estrangeiras, como os EUA nesse cenário, mas poderia mais facilmente reconhecer que a tensão era derivada de um malentendido por conta da diversidade cultural presente nas Operações de Paz.

Com isso, o outro exemplo selecionado para evidenciar como se dá o diaa-dia dos Assistentes de Linguagem está inserido dentro de uma Companhia de Engenharia de Paz. Por ser uma seção de trabalhos técnicos da área de engenharia, os intérpretes possuem um trabalho de comunicar a população o que está ocorrendo. Uma operação de asfaltamento, por exemplo, impacta diretamente na vida da população local, uma via estará momentaneamente obstruída, haverá barulho e sujeira na área.

Desse modo, cabe ao Assistente de Linguagem informar aos locais presentes o que está sendo feito, ou seja, prover avisos que a tropas consideram de conhecimento da população. Sem ser exaustiva, podemos considerar exemplos como avisar que crianças não podem brincar por perto, explicar o planejamento da obra e sua duração. Da mesma forma que a falta de um intérprete pode comprometer o primeiro exemplo, podemos imaginar riscos para o segundo. 


\section{ii. Formação dos Assistentes de Linguagem na MINUSTAH}

Já nesta parte, procuro apresentar algumas contradições entre as realidades e visões de diferentes atores no terreno. Busco mostrar que a própria categoria de Assistentes de Linguagem é ampla, mesmo com exames de qualificação para o processo seletivo, mas também que a diversidade de percepções que atores no terreno adotam sobre a função e a qualificação dos intérpretes locais.

Kelly \& Baker (2013) afirmam que com a institucionalização dos intérpretes em um Operação de Paz, é comum criar um processo seletivo que inclui testes sobre a proficiência do profissional, que variam de missão para missão. Porém, como veremos abaixo, eles não costumam ser suficientes para medir as dificuldades que um Assistente de Linguagem terá ao trabalhar com interpretação em um ambiente hostil.

Quando questionado sobre sua qualificação, o intérprete local entrevistado apontou que já tinha alguma experiência na área e, por isso, conseguia realizar sua função sem grandes desafios, diferente de alguns colegas. Já, o intérprete militar, que possuía uma função de o chefe da seção de Tradução e Interpretação, supervisionando os Assistentes de Linguagem na Companhia de Engenharia de Força de Paz, indicou que a maioria dos intérpretes locais com quem trabalhou só possuíam o grau de escolaridade equivalente ao Ensino Médio brasileiro, mesmo que houvesse algum conhecimento de português e/ou inglês com a vinda da MINUSTAH, para além de francês e créole:

\footnotetext{
Mas no terreno, quando eu encontrei os Assistentes de Linguagem eu já sabia dos seus limites: que eram pessoas não treinadas, que tinha um determinado nível de escolaridade, mas não tinham passado por um treinamento técnico nem de tradução, nem de interpretação. Em sua maioria, aprendeu um idioma estrangeiro até para facilitar na sobrevivência. Então, esses profissionais não tinham a qualificação técnica para desenvolver um trabalho de tradução e interpretação. Assim sua função era apoiar, não necessariamente fazer aquele serviço profissional (...). Então, o Assistente de Linguagem fazia meio que um intermédio, ele intermediava a conversa, mas ele não fazia uma interpretação [profissional], porque ele não tinha sido treinado para isso (Intérprete militar brasileiro, grifo nosso).
}

Essa ausência de um treinamento formal também foi questionada devido a uma dificuldade enfrentada pelo intérprete militar. Seu cotidiano incluía, além de traduções técnicas português-inglês de documentos entre o batalhão brasileiro e o Quartel-Geral da missão, preencher formulários semanais e mensais que avaliavam a performance de cada Assistentes de Linguagem. Mesmo com a 
possibilidade de demissão com uma má avaliação, ele pontuou que passou por dificuldades com alguns intérpretes. Nesse caso, precisou recorrer à seção de Assistentes de Linguagem da Unidade de Pessoal da MINUSTAH (semelhante aos Recursos Humanos) para tratar de um intérprete local que não cumpria o expediente completo ou desaparecia no meio de uma missão.

Fui conversar com o chefe daquela seção, que era responsável por todos os Assistentes de Linguagem da MINUSTAH, não só os do meu contingente. Ele me fez a mesma pergunta, quer dizer, me disse para treiná-los. Ora, eu não tenho que treiná-lo, quem deve fazê-lo é a missão, que por sua vez, a gente já sabe que eles são "não treinados". Eles são denominados not trained ou untrained professionals. A questão é eu sei o limite desse profissional. O problema não é a ausência de treinamento, mas é pontualidade, falta de comprometimento; são outros fatores (...). Há uma dificuldade muito grande de mandar alguém embora, porque o chefe deles também é um haitiano. Aí, existe um senso protetor, uma vontade de proteger. A gente até entende, não é que a gente concorde. Eles querem se proteger, se blindar. Mas é muito difícil mandar alguém embora, tem que ter um problemão. Normalmente, eles tiram do seu [batalhão/contingente] e jogam em outro. Tira o problema daqui e joga lá. (Intérprete militar brasileiro).

Apesar de não treinar os Assistentes de Linguagem que trabalhavam em seu contingente, o entrevistado comentou que considera fundamental oferecer alguma orientação para os intérpretes sobre como agir em uma reunião, para garantir sua segurança e a da tropa presente. Isso significa que o Assistente de Linguagem recebia indicações do que era esperado dele e pequenos ajustes em sua performance. Vale, ainda, ressaltar que os intérpretes locais estão cumprindo o papel de apoiar o componente, não o contrário. A título de exemplo, eles eram orientados a não conversar diretamente com a população quando estavam trabalhando para a ONU em uma missão.

Outro tipo de preparação essencial apontada por ambos os entrevistados é quando os peacekeepers informam com uma certa antecedência sobre que tipo de encontro o Assistente Linguagem deverá atuar. É reconhecido por ambos que há uma questão de sigilo envolvida, todavia, algum tipo de contextualização ajuda qualquer intérprete (profissional ou não) a reunir um vocabulário relacionado à situação, que pode auxiliar em sua performance. Mesmo assim, eles afirmaram isso não faz parte do cotidiano das Operações de Paz.

Como último exemplo desta seção, gostaria de investigar uma questão mais técnica da área de Tradução e Interpretação, relacionada à fidelidade da interpretação ao texto original. Sandra Hale (2007), como outros autores da área, aponta que há uma certa preferência por uma equivalência pragmática em relação à semântica, ou seja, a transposição da mensagem deve levar em conta as peculiaridades do contexto, indo além de uma tradução/interpretação palavra por palavra respeitando uma estrutura gramatical. 
Contudo, levando em consideração um contexto de insegurança inerente à uma Operação de Paz como a MINUSTAH, há o debate sobre a alteração do conteúdo da mensagem preocupando-se com a polidez. Por um lado, o intérprete profissional defende que não cabe a um intérprete fazer nenhuma alteração da mensagem, principalmente quando se trata da conotação de termos que podem apontar a atmosfera da situação. A título de exemplo, podemos imaginar uma reunião entre peacekeepers e um líder local, sendo mediada por um Assistente de Linguagem. Se o representante local usa palavras de baixo calão e/ou pejorativas, o que pode apontar uma insatisfação em relação à presença daquela tropa, ou seja, uma possível situação de insegurança, o intérprete não deve oculta essa informação.

Por outro lado, o intérprete local entrevistado pontuou que era necessário fazer esse tipo de alteração, com a finalidade de manter a situação a mais amigável e pacífica possível, isto é, um posicionamento contrário à visão do Major. Podemos imaginar que, se algo de ruim for dito por um dos lados, o próprio intérprete por estar repassando a mensagem pode ser apontado como culpado ${ }^{23}$. Outro motivo para essa divergência de opinião pode estar relacionado ao código ético da profissão, por serem intérpretes não profissionais e talvez não terem recebido um treinamento que difundisse esses valores.

\section{iii. Desafios do Emprego dos Assistentes de Linguagem na MINUSTAH}

Apesar de alguns desafios já terem sidos expostos na divisão anterior, aqui busco refletir sobre alguns casos não relacionados à formação do Assistente de Linguagem. Quando se pensa em um contexto de Operações de Paz, principalmente quando há uma autorização de um maior uso da força como é o caso da MINUSTAH, há também uma questão de risco de vida inerente às suas atividades. Nos mandatos, por exemplo, é rotineiro a preocupação de garantir a segurança do pessoal empregado pela ONU.

Mesmo assim, nem sempre é possível garantir a vida dos empregados locais. Como anteriormente mencionado, essas pessoas não moram nas bases, logo estão expostos a sequestros para extração de informação, bem como podem ser mortos como uma mensagem de um spoiler sobre o apoio da população local a organizações internacionais, como a ONU. Um exemplo disso é o relato do intérprete local entrevistado de que um de seus amigos foi assassinado por uma

\footnotetext{
23 Algumas expressões relacionadas à pratica da comunicação são relevantes para esse cenário como a em inglês "don't shoot the messenger", que busca refletir sobre como a culpa do problema não é da pessoa que informa sobre ele.
} 
das milícias haitianas em 2006. Os assassinos tinham como objetivo matar o entrevistado, uma vez que descobriram que ele trabalhava como intérprete para a MINUSTAH, mas acabaram confundindo-o com seu amigo.

O intérprete militar brasileiro entrevistado comentou sobre esse caso, afirmando que os Assistentes de Linguagem, bem como outros funcionários locais, são alertados do risco de serem retaliados pela própria comunidade. No entanto, mencionou que a tropa brasileira presente no Haiti procurou se destacar nesse quesito, uma vez que sempre buscou garantir a segurança dos intérpretes locais com que trabalhava. Ele aponta dois casos específicos.

Para o primeiro, é importante recordar que havia na época da participação do entrevistado na MINUSTAH um problema de iluminação pública, ou seja, quando estava no final do dia já existia uma preocupação dos Assistentes de Linguagem em irem para casa, uma vez que no escuro há uma probabilidade maior de insegurança, aumentando a criminalidade. Entretanto, como havia com uma certa frequência tarefas a serem executadas até mais tarde, o componente brasileiro fornecia abrigo e refeição no escritório da ONU para que o intérprete não colocasse sua vida em risco por precisar voltar para casa à noite.

O outro caso abordado é, por exemplo, ações que envolviam o acompanhamento dos Assistentes de Linguagem em missões fora da base, como por exemplo ida a bancos:

Outra preocupação é o intérprete ao trabalhar com os componentes, principalmente com o militar. Ele passa a ser responsabilidade da tropa. Enquanto ele está inserido naquele contexto, ele vai ser responsabilidade daquela tropa. $\mathrm{E}$ assim é feito. Então se todos formos de colete e capacete, ele também vai. A gente providencia o equipamento e eles reclamavam muito, porque pesa. Vai de colete e capacete e não pode tirar. E vamos lá, porque é a integridade. Acabou a missão, no retorno para a base, está passando perto da casa dele [Assistente de Linguagem], ele pode descer ali e ir para casa? Ele até quer, ele vai pedir: "pode me deixar aqui que eu vou, minha casa já é ali". "Não, saímos da base, voltamos todos para a base". Se chegou lá e está tarde demais, não há problema, ele fica lá mesmo, vai embora no dia seguinte, por questões de segurança. (Intérprete militar brasileiro)

Ele acompanhava a parte de pagamentos. Isso, porque ir ao banco no Haiti significa falar crioulo no banco. Ele ia ao banco junto, de colete, capacete, tudo que for necessário. Afinal estávamos movimentando uma grande quantidade de dinheiro e a proteção era necessária. (Intérprete militar brasileiro)

O último desafio que busco abordar se trata do treinamento dos peacekeepers que vão fazer uso do serviço. Pode parecer trivial, já que o intérprete vai transmitir a mensagem em outro idioma e repassar a informação para as tropas. Porém, há diversos cuidados que a pessoa que discursa deve levar em consideração. Para além da necessidade de um briefing antes da 
reunião, como citado anteriormente, é necessário que o locutor faça frases curtas e respeite o tempo mínimo para o intérprete falar, caso seja uma interpretação consecutiva (mais comum na MINUSTAH segundo os entrevistados). Cabe lembrar também que o peacekeeper deve sempre se dirigir à audiência, enquanto que o Assistente de linguagem deve estar ao lado ou atrás do mesmo para evitar que o intérprete seja confundido como o dono do conteúdo sendo debatido.

Desse modo, cabe aos membros dos contingentes mobilizados trabalhar com esses profissionais para ter o conhecimento de como melhor usufruir do serviço. Esse, para intérprete profissional, acaba sendo um dos principais desafios no terreno. Mesmo que haja um módulo de treinamento formal sobre o uso de Assistentes de Linguagem estipulado nos STMs, ele não é suficiente. Ele ainda cita que a ONU não fiscaliza fortemente o treinamento de cada país contribuinte, portanto, somente uma indicação de um módulo sobre uso de intérpretes locais não prepara totalmente o peacekeeper para o terreno.

Como busco mostrar neste artigo, os Assistentes de Linguagem são profissionais essenciais para o andamento de qualquer Operação de Paz, porque conseguem realizar a mediação entre a ONU e as comunidades locais. Todavia, não há a devida visibilidade para os intérpretes locais com uma política institucionalizada, como há para questões tão importantes quanto a que é tratada neste artigo, como por exemplo, combater o Abuso e Exploração Sexual e para proteção de crianças envolvidas em conflitos armados.

\section{Considerações Finais}

O artigo refletiu sobre os principais desafios e potencialidades do emprego de Assistentes de Linguagem em Operações de Paz. Neste sentido, optou-se por uma empiria ancorada pelas entrevistas e relatos de profissionais que demonstram a atuação desses intérpretes locais especialmente na MINUSTAH. Dessa forma, a partir das experiências sobre as realidades dos entrevistados, foi possível que observássemos como é operacionalizada a atuação dos Assistentes de Linguagem no seu cotidiano em meio às múltiplas situações de estresse inerentes em uma Operação de Paz.

Diante disto, a partir de um olhar para as práticas do cotidiano evidenciadas nas entrevistas, pode-se constatar sem romantizar como os Assistentes de Linguagem promovem uma sinergia, seja linguística e/ou cultural, entre os componentes da Operação de Paz e a comunidade local. De fato, com 
proficiência, profissionalismo e sensibilidade cultural, esses trabalhadores se transformam em assets.

Assim sendo, a ausência de uma agenda ou um escritório que busque tratar desses profissionais e de sua contribuição para a paz é prejudicial para os esforços da ONU. Concomitantemente, limitados são os trabalhos que problematizam a interação e participação destes atores enquanto forma de produção de conhecimento, tendo em vista as suas limitações e paradoxos. Torna-se evidente, portanto, que este artigo busca lançar luz sobre a problemática, a fim de instigar um debate por meio do ferramental prático nas Relações Internacionais, sobretudo e principalmente, quando é possível observar o quão complexo e ambíguo se constitui a figura dos Assistentes de Linguagem em uma Operação de Paz da ONU.

\section{Referências Bibliográficas}

ADLER, E; POULIOT, V. International practices: introduction and framework. In: (Eds.). International Practices. Nova York: Cambridge University Press, 2011.

ANTONINI et al. Introducing NPIT studies In: ANTONINI et al. (Ed.). Nonprofessional Interpreting and Translation. State of the art and future of an emerging field of research. Amsterdam / Philadelphia: John Benjamins Publishing Company, 2017, p. 1-28.

BAKER, C. The Care and Feeding of Linguists: The Working Environment of Interpreters, Translators, and Linguists During Peacekeeping in BosniaHerzegovina. War \& Society, v. 29, n. 2, 2010, p. 154-175. DOI: $10.1179 / 204243410 \times 12674422128993$

BISCHOFF, A.; LOUTAN, L. Other Words Other Meanings. Genebra: Hôpitaux Universitaires de Genève, 2008.

BUEGER, C. Pathways to practice: praxiography and international politics. European

Political Science Review, v. 6, n. 3, p. 383-406, 2014. DOI:10.1017/S1755773913000167. 
BUEGER, C; GANDIGER, F. International practice theory: new perspectives. Londres: Palgrave Macmillan, 2014. . The Play of International Practice. International Studies Quarterly, v. 59, n. 3, 2015, p. 1-12. DOI: 10.1111/isqu.12202.

BUSINARO, R. Relief operations across language barriers: the interpreter factor. 2012. Dissertação (Mestrado em Ação Humanitária), University College Dublin, Dublin.

CONSELHO DE SEGURANÇA DA DAS NAÇÕES UNIDAS. Report of the Secretary-General on Haiti. S/Index: S/2004/300, 16 de abril de 2004a. Disponível em: <https://www.securitycouncilreport.org/atf/ct/\%7B65BFCF9B6D27-4E9C-8CD3-CF6E4FF96FF9\%7D/Haiti\%20S2004300.pdf>. Acesso em 20 jun. 2019.

Resolução S/RES/1529. S/Index: S/RES/1529, 29 de fevereiro de 2004b. Disponível em: <https://www.securitycouncilreport.org/atf/cf/\%7B65BFCF9B6D27-4E9C-8CD3-CF6E4FF96FF9\%7D/Chap\%20VII\%20SRES\%201529.pdf>. Acesso em 20 jun. 2019.

Resolução S/RES/1542. S/Index: S/RES/1529, 30 de abril de 2004c. Disponível em: <https://www.securitycouncilreport.org/att/cf/\%7B65BFCF9B6D27-4E9C-8CD3-CF6E4FF96FF9\%7D/CAC\%20SRES\%201542.pdf>. Acesso em 20 jun. 2019.

DE CONING, C. Is stabilization the new normal? Implications of stabilization mandates for the use of force in UN peacekeeping operations. In: The use of force in UN peacekeeping. Nova York: Routledge, 2018, p. 85-99.

DOYLE, M. Liberal Peace: Selected Essays. London and New York: Routledge, 2012.

EDWARDS, V. The Role of Communication in Peace and Relief Missions and Negociations. Translation Journal, 2001. Disponível em: <https://translationjournal.net/journal/20interpr.htm>. Acesso em: 13 mar. 2019.

FOLEY, C. UN Peacekeeping Operations and the Protection of Civilians. New York: Cambridge University Press, 2017. 
GENTILE, A. Community Interpreting or Not? Practices, Standards and Accreditation. In; S. Carr, R. Roberts, A. Dufour, and D. Steyn (eds.). The Critical Link: Interpreters in the Community. Amsterdam/Philadelphia: John Benjamins, 1997.

GIL, A. Métodos e Técnicas de Pesquisa Social. 6 ed. São Paulo: Atlas, 2008.

GORUR, A. Defining Boundaries UN Stabilization Missions, 2016. Disponível

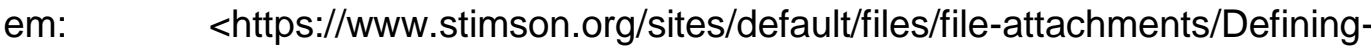
Boundaries-UN-Stabilization-Missions.pdf>. Acesso em 09 jun. 2019.

HALE, S. Community Interpreting. London: Palgrave Macmillan, 2007.

HAMANN, E; GARBINO, H; FOLLY, M. Confiança em desenvolvimento: o Brasil e os projetos de impacto rápido. Instituto Igarapé, 2017. Disponível em: <file://C:/Users/vitti/Documents/.\%20PUC/2019.2/Globaliza\%C3\%A7\%C3\%A3o, \%20Pol\%C3\%ADtica\%20e\%20Cultura\%20(IRI1601)/AE-24_Confiana-emdesenvolvimento-14-04-web-BR.pdf >. Acesso em 09 dez. 2019.

HUNT, C. All necessary means to what ends? The unintended consequences of the 'robust turn' in UN peace operations. International Peacekeeping, vol. 24, n. 1, p. 108-131, 2017. DOI: 10.1080/13533312.2016.1214074.

KALDOR, M. In Defence of New Wars. Stability, vol. 2, n. 1, 2013, p. 1-16. DOI: http://dx.doi.org/10.5334/sta.at

KARLSRUD, J. From Liberal Peacebuilding to Stabilization and Counterterrorism. International Peacekeeping, vol. 26, n. 1, 2019, p. 1-21. DOI:10.1080/13533312.2018.1502040.

KELLY, M; BAKER, C. Interpreting the peace - Peace Operations, Conflict and Language in Bosnia-Herzegovina. Londres: Palgrave Macmillan, 2013.

KENKEL, K. Five generations of peace operations: from the "thin blue line" to "painting a country blue". Revista Brasileira de Política Internacional. vol. 56. n.1. 2013. 
KIPMAN, I. Lições de humanidade e solidariedade. In: BRAGA, C; FERREIA, A (Org.). 13 anos do Brasil na MINUSTAH: lições aprendidas e novas perspectivas. Rio de Janeiro: Centro de Instrução Almirante Sylvio de Camargo, 2019.

MAC GINTY, R. Against Stabilization. Stability: International Journal of Security \& Development, vol. 1, n. 1, p. 20-30, 2012. DOI:10.5334/sta.ab.

International Peacebuilding and Local Resistance: Hybrid Forms of Peace. Londres: Palgrave Macmillan, 2011.

MOSER-MERCER, B; BALI, G. Interpreting in Zones of Crisis and War. AllC, 2008. Disponível em: <https://aiic.net/page/2979/interpreting-in-zones-of-crisis-andwar/lang/1>. Acesso em: 06 maio 2019.

MUGGAH, R. The United Nations Turns to Stabilization, 2014. Disponível em: $<$ https://theglobalobservatory.org/2014/12/united-nations-peacekeepingpeacebuilding-stabilization/>. Acesso em 08 jun. 2019.

ORGANIZAÇÃO DAS NAÇÕES UNIDAS. United nations peacekeeping operations: principles and guidelines. New York: Department of Peacekeeping Operations and Department of Field Support, 2008.

Negotiation/Mediation and the Use of Language Assistants. Specialized Training Material for Police. vol. 1, 2009. Disponível em: <http://dag.un.org/bitstream/handle/11176/387368/STM\%20Negotiation\%20Medi ation\%20and\%20the\%20Use\%20of\%20Language\%20Assistants.pdf?sequence $=8$ \&isAllowed $=\mathrm{y}>$. Acesso em: 13 mar. 2019.

In Memoriam: In remembrance of those members of the UN Family who lost their lives in the earthquake in Haiti, 12 January 2010, 2010. Disponível em: <https://www.un.org/en/memorial/haiti/>. Acesso em: 30 mar. 2019.

PARIS, R. Peacebuilding and the Limits of Liberal Internationalism. International Security, vol. 22, n. 2, 1997.

RICHMOND, O. UN peace operations and the dilemmas of the peacebuilding consensus. International Peacekeeping, vol. 11, n. 1, pp. 83-10, 2004. 
. Para além da paz liberal? Respostas ao "retrocesso". Contexto

Internacional, vol. 32, n. 2. DOI: 10.1590/S0102-85292010000200002.

ROCHA DE SIQUEIRA, I. Contribuições da Teoria da Prática de Pierre Bourdieu. In: ROCHA DE SIQUEIRA, I. et al. (Org.). Metodologia e Relações Internacionais: Debates Contemporâneos Vol. II. Rio de Janeiro: Ed. PUC-Rio, 2019.

ROGL, R. Language-related disaster relief in Haiti: Volunteer translator networks and language technologies in disaster aid. In: ANTONINI, R. et al. (Ed.). Nonprofessional Interpreting and Translation. State of the art and future of an emerging field of research. Amsterdam / Philadelphia: John Benjamins Publishing Company, 2017. p 231-258.

SENGPUTA, S. UN Apologizes for Role in Haiti's 2010 Cholera Outbreak. New York: New York Times, 1 de Dezembro de 2016. Disponível em: $<$ https://www.nytimes.com/2016/12/01/world/americas/united-nations-apologyhaiti-cholera.html>. Acesso em: 8 out. 2018

SOUZA JÚNIOR, I. Tradução e interpretação militar brasileira em missão de paz da ONU: a relevância de um serviço especializado, 2015. Disponível em: <http://www.ccopab.eb.mil.br/pt/repositorio-de-arquivos/category/15-traducao-einterpretacao-militar-em-op-paz>. Acesso em: 24 nov. 2018.

O uso do assistente de linguagem em missões de paz da ONU, 2016. Disponível em: $<$ http://www.ccopab.eb.mil.br/pt/repositorio-dearquivos/category/17-o-uso-do-assistente-de-linguagem-em-missoes-de-paz-daonu>. Acesso em: 24 nov. 2018.

TRAN, M. Translators fight the fatal effects of the language gap. The Guardian, 2012. Disponível em: <https://www.theguardian.com/global-development/povertymatters/2012/apr/11/volunteers-translation-language-health-messages>. Acesso em 25 maio 2019.

UNITED NATIONS CIVIL-MILITARY COORDINATION. Specialized training materials. $2 . \quad$ ed., $2014 . \quad$ Disponível em: $<$ http://repository.un.org/bitstream/handle/11176/89582/STM\%20UNCIMIC.pdf?s equence $=1$ \&isAllowed $=\mathrm{y}>$. 
UNITED NATIONS PEACEKEEPING. Where We Operate. Disponível em: <https://peacekeeping.un.org/en/where-we-operate>. Acesso em: 13 mar. 2019. 